tumor. During a pain the head showed but little tendency to engage, while the mass posteriorly drove the posterior vaginal fornix markedly forward into the vaginal lumen, the head (apparently normal in size) also becoming more prominently outlinable on the anterior abdominal wall. In a well-formed woman with a normally shaped and situated uterus and with an absence of any pelvic contraction or marked increase in the size of the child's head or other parts above the normal, the only inference possible was the presence of a mechanical obstruction probably due to a tumor in the cul-de-sac of Douglas. Attempts to reposit the obstructing tumor above the pedvic brim while the patient was in the knee-chest position were fruitless.

Operation.-Preparations were immediately begun and the abdomen opened by a $12 \mathrm{~cm}$. median (Wagner) incision extending from the umbilicus downward toward the pubis. Com. presses were now carefully packed between the abdominal wall and the uterus (in situ) to avoid contamination of the peritoneal cavity. The uterus was then also incised in the anterior median line, upper third, encountering the placenta, which was rapidly shelled off at one edge and the child rapidly delivered, the cord doubly clamped, and divided. The afterbirth was now rapidly delivered when the uterus retracted. The uterine in-

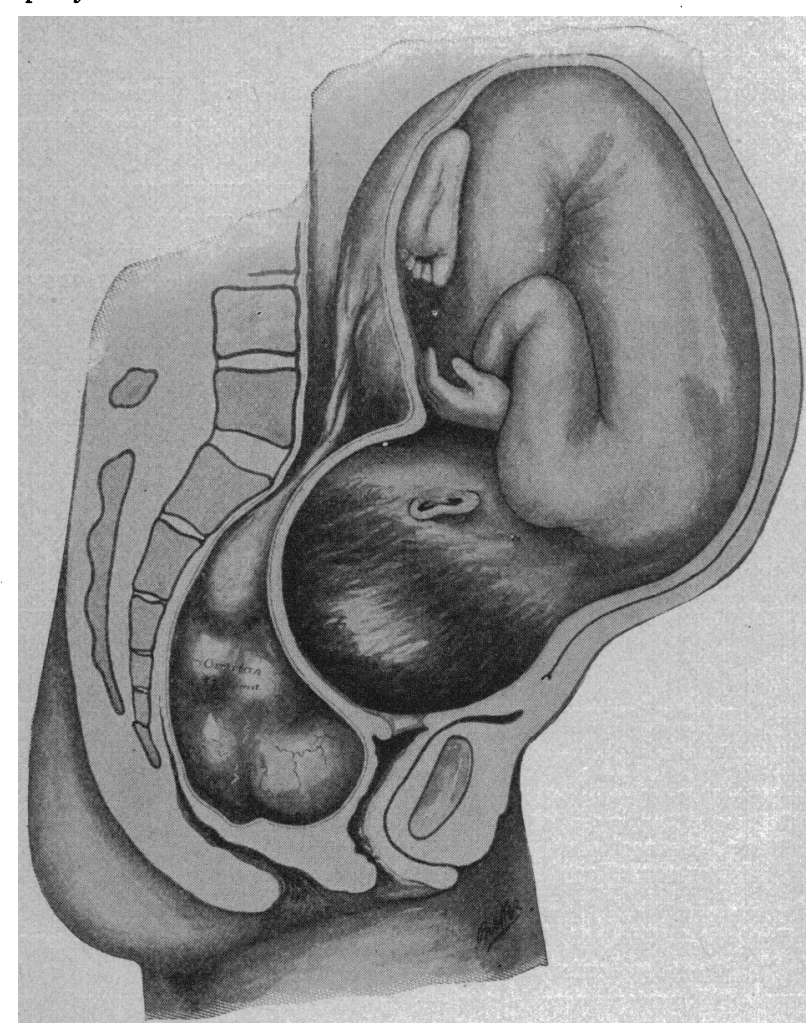

An ovarian cystoma obstructing labor at term.

cision was now closed by catgut ì étages, and all compresses being removed, the exploration of the cul-de-sac revealed a cystoma firmly incarcerated under the promontory. The patient was now placed in the Nélaton position and the intestines walled off with fresh compresses. The tumor was then lifted out of the cul-de-sac of Douglas and delivered whole, its long, thin pedicle ligated, divided and the stump covered with peritoneum. The abdominal incision was now closed with catgut and through-and-through silkworm-gut sutures. The mother made an uneventful recovery. Lnfortunately, thougi the child was delivered within one hour of the time 1 first saw the case, it could not be resuscitated.

Tumor.-The cystoma was approximately of the size and tenseness of a half-filled two-quart fountain syringe, and as it lay on a flat surface measured $15 \times 19 \times 4 \mathrm{~cm}$. Probably a more tense cyst could have been more easily displaced up. wards.

The case is unique from the standpoint that the tumor must have becn present before pregnancy began, and teaches the necessity, at as early a date as possible in every pregnancy, of making a careful and systematic examination (a) as to whether there is any tumor present; (b) whether the pregnancy be intrauterine or extrauterine; (c) whether the uterus be retroverted, and (d) whether the pelvis is contracted or of normal dimensions.

100 State Street.

\section{MOLD FOR CARBON DIOXID SNOW}

\section{R. L. SUTTON, M.D.}

KANSAS CITY, Mo.

When carbon dioxid snow is employed as a destructive agent in skin lesions it must first be molded into suitable shape. If a large area is to be attacked a closely packed mass of the substance may be altered as required by means of a sharp knife, but in the majority of instances a "peneil" best answers the purpose.

In making these cylinders the snow is quickly transferred from the chamois, where it collects as it escapes from the reservoir, to a matrix or form, into which it is tightly pressed by means of a small rammer. The

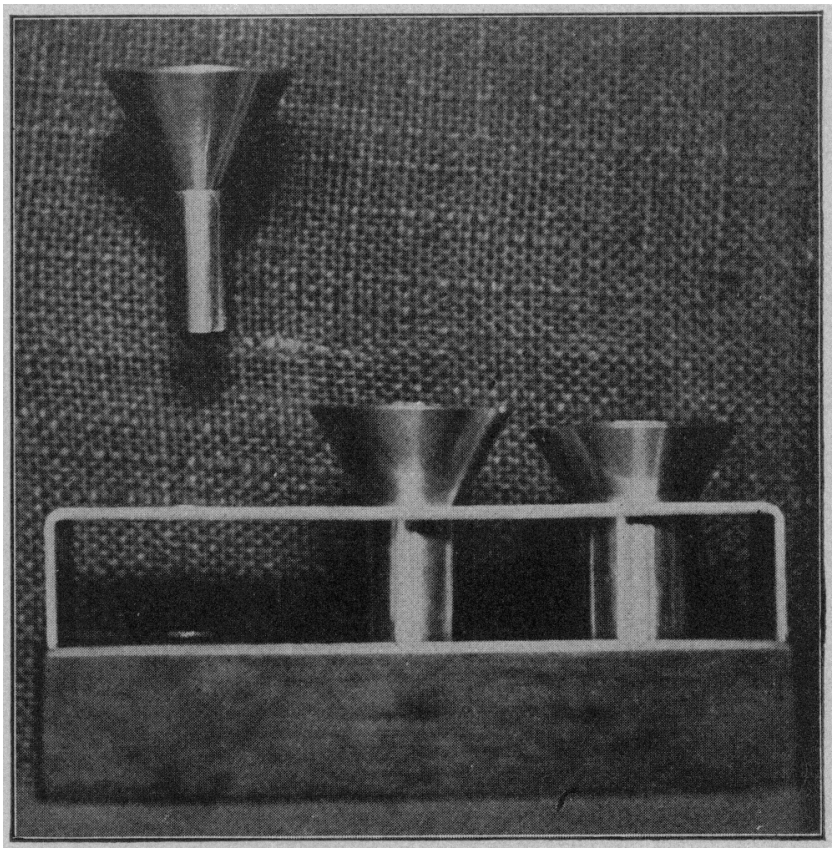

Mold for carbon dioxid snow.

form or mold commonly employed is simply a short piece of hard rubber, glass or metal tubing. No one but a person who has had experience in filling these small caliber tubes realizes the waste of time and material the process usually entails.

I have had made of German silver a set of three funnel-mouthed tubes, which renders this procedure a speedy and economical one. The internal diameter of the barrels measure 1,2 and $4 \mathrm{~cm}$. , respectively, and all are of the same length, $4 \mathrm{~cm}$. The freshly-made snow is transported from the chamois to the molds by means of a teaspoon.

Further to expedite matters the molds are set upright in a frame, the lower ends being sunk slightly below the surface of the platform. When the tube is filled the mold is withdrawn from the frame and the stick of snow pushed out. 